\title{
Emerging Biogeochemical Views of Earth's Ancient Microbial Worlds
}

Timothy W. Lyons ${ }^{1}$, David A. Fike², and Aubrey Zerkle ${ }^{3}$

\begin{abstract}
Microbial processes dominate geochemical cycles at and near the Earth's surface today. Their role was even greater in the past, with microbes being the dominant life form for the first $90 \%$ of Earth's history. Most of their metabolic pathways originated billions of years ago as both causes and effects of environmental changes of the highest order, such as the first accumulation of oxygen in the oceans and atmosphere. Microbial processes leave behind diverse geochemical fingerprints that can remain intact for billions of years. These rockbound signatures are now steering our understanding of how life coevolved with the environments on early Earth and are guiding our search for life elsewhere in the universe.
\end{abstract}

\section{KEYWORDS}

early Earth, microbiology, environmental change, biogeochemical cycles, biosignatures, isotopes, astrobiology

\section{INTRODUCTION}

The history of life on Earth is reconstructed in many ways-some more convincing than others. Fossil remains of early stromatolites and microfossils give us our first physical glimpses of life about 3.5 billion years ago (3.5 Ga). But the story begins even earlier, with subtle biosignatures locked in the chemical compositions of sedimentary rocks. In fact, biogeochemical records track the presence and activities of past life throughout Earth history. They occur as direct and indirect chemical fingerprints of microorganisms living within and beneath the oceans and on the continents. The direct records are molecular

\footnotetext{
1 Dept. of Earth Sciences

University of California, Riverside, CA 92521 USA

E-mail: timothy.lyons@ucr.edu

${ }^{2}$ Dept. of Earth \& Planetary Sciences

Washington University

St. Louis, MO 63130 USA

E-mail: dfike@levee.wustl.edu

${ }^{3}$ Dept. of Earth \& Environmental Sciences

University of St Andrews

St Andrews, KY16 9AL, Scotland UK

E-mail: az29@st-andrews.ac.uk
} 
fossils, or organic biomarkers, that can be tied, with varying degrees of certainty, to their primitive prokaryotic or eukaryotic sources. Biomarkers are not at their best in the search for the earliest life on Earth, as they can suffer thermal breakdown during long burial, but they can provide remarkable windows into early life in less mature materials.

Inorganic expressions of biological processes are often more resilient than organic biomarkers, although they too must be viewed with healthy skepticism. When used carefully, however, these indirect records allow us to look for the chemical products of metabolic pathways that can be tied to microbial life on the early Earth and elsewhere within, and potentially beyond, our Solar System. These biogeochemical signals include distinct isotopic fractionations that are unique to specific metabolisms or that hint at the accumulation of waste-product gases, such as oxygen or methane. Abundances of certain elements (such as sulfur and iron) in the oceans through time, as constrained by enrichment patterns in sedimentary rocks, point to the metabolic processes that microbes use to cycle these elements. At the same time, the availability of trace metals that form essential enzymatic cofactors in diverse biogeochemical cycles can both drive and be driven by shifting redox conditions at Earth's surface.

Studies of modern microorganisms under controlled experimental and natural conditions as analogs for the past have yielded a catalog of biosignatures, particularly isotopic effects, across gradients spanning temperature, quantity and quality of electron donors, availability of micro- and macronutrients, and $\mathrm{pH}$. Space does not allow us to outline the full catalog of these biosignatures or all their implications in deep time, but we can offer a hint of what is possible. We begin with a broad overview of the early Earth - that is, the first $90 \%$ of Earth's history when microorganisms would have grabbed most of the headlines in stories about global change.

\section{ROADMAP OF EARLY MICROBIAL LIFE}

The oldest signs of animal life appear in the geologic record a bit more than 600 million years ago (600 Ma) (Love et al. 2009). For the four billion years before that, our planet experienced dramatic changes that paved the way for this milestone (reviewed in Lyons et al. 2014). Oxygen isotope analysis of detrital zircon grains tell us that Earth's oceans got an early start, perhaps 4.3 billion years ago. Other than this essential, life-affirming step, the single most important environmental transformation in history may have been the first permanent rise of atmospheric oxygen, which took place around 2.3 to $2.4 \mathrm{Ga}$ and is termed the Great Oxidation Event (GOE) (FIG. 1). Before then, Earth's atmosphere and oceans were, at best, intermittently and locally oxygenated and probably at very low levels. Yet key questions 
remain about the timing and triggers of the first biological $\mathrm{O}_{2}$ production, now tentatively placed by some researchers at 3.0 Ga (Crowe et al. 2013; Planavsky et al. 2014a). Recent studies have revealed the difficulties that can be associated with interpretations of very early organic biomarker records in highly heated rocks. This challenge places the burden of proof for the earliest oxygenic photosynthesis (by cyanobacteria) on the inorganic side of the geochemical ledger.

The current record holders for the earliest physical signs of microbial life on Earth are putative $~ 3.5$ Ga stromatolites and microfossils from northwestern Australia (FIG. 1). The oldest geochemical clues are still-debated carbon isotope fingerprints of autotrophy in $\sim 3.7$ to $3.8 \mathrm{Ga}$ rocks from southwestern Greenland. Isotopic and elemental data suggest active microbial cycling of methane, nitrogen, iron, manganese, and sulfur that predates the GOE by hundreds of millions of years (e.g. methanogenesis and methanotrophy [KrissansenTotton et al. 2015]; manganese oxidation inferred from trace metal data [Crowe et al. 2013; Planavsky et al. 2014a,b]; iron reduction [Heimann et al. 2010] perhaps following photoferrotrophy [anoxygenic photosynthetic oxidation, Kappler et al. 2005]; and diazotrophy [nitrogen fixation, Stüeken et al. 2015]). Some microbial fingerprints are even older (e.g. sulfate reduction: Shen et al. 2001), and there are other signatures of early oxidative pathways, particularly as the GOE approached (e.g. sulfide oxidation and coupled nitrification/denitrification: Godfrey and Falkowski 2009).

Recent work suggests that the initial rise of atmospheric oxygen may have been protracted, occurring in fits and starts rather than a single step. Once permanently present in the atmosphere at the GOE, oxygen likely rose to very high levels soon thereafter during a prolonged period of very positive carbon isotope values in the oceans. Following a few hundred million years of potentially very high oxygen levels in the ocean and atmosphere, concentrations seem to have dropped dramatically. At least a billion years of dominantly oxygen-free conditions in deep ocean waters followed, beneath an atmosphere that may still have been oxygen poor.

Deficiencies in oxygen and associated nutrients may have set a challenging course for many of the oceans' simple microscopic inhabitants, causing persistently low populations and diversities of the earliest eukaryotic organisms (Anbar and Knoll 2002). This biogeochemical "stasis" was likely tied to nutrient cycling, possibly colimitation of nitrogen and trace metals in particular, and involving complex feedbacks in the early oceans that differed dramatically from today's cycles. These environmental throttles may have allowed primary biological production and oxygen in the oceans and atmosphere to persist at levels low enough to delay the first appearance of animals. The newest data suggest that these billion-plus years of 
"intermediate" oxygen and life were followed by increases in oxygen, which by roughly 800 Ma appears to anticipate the emergence and diversification of animals (Planavsky et al. 2014b) - this latter period of oxygen increase is sometimes known as the Neoproterozoic Oxidation Event, or NOE (FIG. 1). Even so, it is likely that this pattern of dynamic (rising and falling) oxygenation continued throughout the Neoproterozoic and into the Paleozoic.

The emerging story is one where the initial and subsequent oxygenations were far more dynamic than previously thought, characterized both by rising and falling levels in the oceans and atmosphere, and long periods of sustained low concentrations even after that initial permanent accumulation in the atmosphere. Microbial evolution was at the center of it all as both a cause and a consequence of the coevolving chemical conditions in the oceans and atmosphere. Our questions about these early patterns and cycles demand that we extract isotopic and elemental biosignatures along with environmental proxies that speak of the presence and abundance of microorganisms and of their specific metabolisms, even in the absence of fossils and diagnostic organic molecules.

Our interpretative power has increased dramatically in recent years as we dissect modern analog systems in the lab and field and identify their potentially preservable biogeochemical signatures. In the following sections, we highlight some of these biosignatures, including important isotopic fingerprints, and the diverse microbiological details they can capture. In doing so, we also provide some perspective on the historical archives of microbial life in sedimentary rocks and on the potentially profound implications of microbial evolution.

\section{ELEMENTAL AND ISOTOPIC PERSPECTIVES}

\section{Carbon Cycling}

At the heart of everything is organic carbon-as a product of microbial activity and as an energy source (electron donor) in the myriad pathways of organic degradation and elemental cycling. For example, the production of organic compounds by cyanobacteria and their burial were responsible for the initial oxygenation of Earth's atmosphere and oceans. A suite of metabolically and physiologically diverse organisms (bacteria, archaea, and eukaryotes) mediates carbon cycling in modern environments. This metabolic activity enables the fixation of carbon as new biomass. Carbon fixation and the formation of carbonate minerals are the two dominant sinks of carbon that, when balanced against the inputs (volcanic, riverine, and hydrothermal), give rise to the geologic carbon cycle. Stable isotope records for carbonate rocks $\left(\delta^{13} \mathrm{C}_{\mathrm{carb}}\right)$ and organic matter $\left(\delta^{13} \mathrm{Corg}\right)$ from these phases provide the best means to reconstruct the carbon cycle over Earth history. 
Despite important recent advances, carbon isotope records remain puzzling, suggesting that there is still much to learn about the fundamental controls and feedbacks that regulate global carbon cycling and its relationship to biospheric oxygenation. For example, the long-term $\delta^{13} \mathrm{C}_{\text {carb }}$ record of marine carbonates is tightly clustered around $0 \%$. Because of a large isotopic fractionation during biological carbon fixation, the relative $\delta^{13} \mathrm{C}$ compositions of organic matter and carbonate are offset by $\sim 30 \%$, and the weighted average of their steadystate burial should reflect the net $\delta^{13} \mathrm{C}$ composition of volcanic, riverine, and hydrothermal inputs to the oceans (estimated today at $-5 \%$ ). Thus, the clustering of $\delta^{13} \mathrm{C}_{\text {carb }}$ values around $0 \%$ suggests that the fraction of carbon buried as organic matter (relative to that locked in carbonates) has remained comparatively constant over Earth's history. This isotopic uniformity persisted despite the following three factors: the development of diverse pathways of carbon fixation by microbes and more complex organisms with varying fractionations, the rise of oxygen in the atmosphere and oceans, and the attendant evolutionary and ecological history of wide-ranging microbial pathways that recycle organic matter.

This puzzling carbon isotope record can be interpreted in several ways. First, unknown feedbacks may operate to keep organic carbon burial relatively constant over Earth's history. Second, the information encoded in $\delta^{13} \mathrm{C}$ records may reflect other processes currently beyond our ken. Third, our view of the long-term $\delta^{13} \mathrm{C}$ record is oversimplified (reviewed in Krissansen-Totton et al. 2015). Further, there are notable deviations from the pattern of $\delta^{13} \mathrm{C}_{\text {carb }}$ clustered at $0 \%$, such as the dramatic isotopic excursions following the GOE and during the latter part of the Neoproterozoic Era. The GOE and NOE are times of dramatic environmental change, suggesting there is rich environmental information left for us to mine from composite records of $\delta^{13} \mathrm{C}$ variation over Earth history.

The causal mechanisms responsible for the transient perturbations that drive $\delta^{13} C_{\text {carb }}$ signals to positive or negative values continue to provide exciting research opportunities. Such excursions are particularly abundant and of unusually high amplitude during the Neoproterozoic and earliest Cambrian. Positive anomalies (i.e. transient increases in $\delta^{13} C_{\text {carb }}$ preserved in a stratigraphic package) are interpreted to reflect pulses of increased organic carbon burial and a concomitant increase in oxygen (or elements of equivalent oxidizing power) to the environment. Analogous mechanisms (e.g. decreases in organic carbon burial) have been invoked for negative anomalies. However, these negative excursions are characterized by very low $\delta^{13} \mathrm{C}_{\text {carb }}$ values that are below the assumed input to the oceans $(\sim$ $-5 \%$ ), particularly during the Neoproterozoic. 
If these events reflect the global carbon cycle, they require dynamic forcing and perturbation to the cycle, including the associated microbial processes. More independent data to evaluate the origin of $\delta^{13} \mathrm{C}$ excursions are needed, and research opportunities abound-particularly since many of these carbon isotope excursions in Phanerozoic rocks are associated with mass extinctions. An improved understanding of the causal mechanism(s) behind these $\delta^{13} C_{\text {carb }}$ excursions can be gained by parallel and complementary geochemical analyses, such as redox-sensitive trace elements, organic biomarkers, or other isotopic systems-including that of sulfur.

\section{Sulfur Cycling}

The cycling of sulfur (FIG. 2), like carbon, is intimately coupled to changes in redox conditions at Earth's surface. Sulfur's isotopic variation through time-tracked in tracers of ancient seawater sulfate, for example-can record the balance between oxidative weathering of pyrite $\left(\mathrm{FeS}_{2}\right)$ on the continents and the large-scale burial of pyrite in marine sediments beneath $\mathrm{O}_{2}$-poor oceans. Sulfur cycling in modern environments encompasses reductive processes, such as microbial sulfate reduction; oxidative processes, such as sulfide oxidation; and the disproportionation of intermediate valence compounds (e.g. elemental sulfur [ $\left.\mathrm{S}^{0}\right]$ or thiosulfate $\left[\mathrm{S}_{2} \mathrm{O}_{3}{ }^{2-}\right]$ ). A suite of metabolically and physiologically diverse organisms that are often found in close physical associations mediate these interrelated pathways. In addition, the sulfur cycle is intimately linked to the carbon cycle. More than $50 \%$ of organic matter

microbiologically degraded (oxidized) in some coastal marine sediments occurs via sulfate reduction.

Like the carbon cycle, the sulfur biogeochemical cycle has two dominant sinks: an oxidized component (sulfate evaporite minerals) and a reduced component (pyrite). Microbial sulfur cycling induces an isotopic fractionation between these phases (measured as $\delta^{34}$ S) (FIG. 2). Records of $\delta^{34} \mathrm{~S}$ variation through time are often interpreted as reflecting changes in pyrite burial versus weathering, akin to the organic carbon cycling that drives variation in the $\delta^{13} \mathrm{C}$ record. On time scales $>100 \mathrm{My}, \delta^{13} \mathrm{C}$ and $\delta^{34} \mathrm{~S}$ records are negatively correlated, suggesting a still poorly understood negative feedback mechanism—one that may work to stabilize environmental oxygen availability.

Microbial metabolic activity during sulfur cycling is associated with a particularly wide range of isotopic fractionations, especially when compared to carbon cycling. These isotopic signatures can be diagnostic of particular metabolic pathways and/or rates of activity. Isotopic offsets between sulfate and pyrite in marine sediments are often much larger (up to 
$70 \%$ ) than fractionations observed in laboratory experiments of sulfate-reducing organisms (typically $<46 \%$ ).

This disparity spawned a many-decades-long mystery, leading Canfield and Teske (1996) to suggest that disproportionation of sulfur intermediates, which increases the isotopic fractionation between sulfate and sulfide, has played a critical role in many marine settings today and throughout much of the last 600 million years. Given that these intermediate species form through partial oxidation of hydrogen sulfide, often through microbial mediation, greater fractionations in the latest Precambrian would be consistent with increasing biospheric oxygenation at that time. However, recent experiments and incubations with natural populations of sulfate reducing microbes have shown that fractionations of up to $70 \%$ can be produced by sulfate reduction alone, even in low-sulfate environments (Canfield et al. 2010; Sim et al. 2011). Thus, there are multiple pathways to producing large sulfur isotope fractionations.

Currently, much work is centered on understanding the relative impacts on environmental sulfur isotope fractionation arising from the type of metabolic pathways (e.g. the presence/absence of sulfur disproportionation) versus the activity of microbes that make use of particular pathways (e.g. role of cell-specific rates of sulfate reduction). Micron-scale investigations by Fike et al. (2009) of microbial mats suggest there is a decrease in isotopic fractionation between sulfate and sulfide at the chemocline-the redox interface with conditions that favor both disproportionation and enhanced rates of sulfate reduction in close proximity. The data from these environments suggest that sulfate reduction rate, rather than the variety of metabolic pathways, may be the controlling factor in determining environmental isotopic fractionation.

Isotopic offsets between oxidized (sulfate) and reduced (pyrite) sulfur also provide temporal constraints on the origins of microbial sulfate reduction, with current estimates extending back to at least $3.5 \mathrm{Ga}$ (Shen et al. 2001). These records of microbial sulfur cycling also carry suggestions of vanishingly low sulfate availability in the early oceans (e.g. Crowe et al. 2014), which further points to trace levels of oxygen in the Archean atmosphere and oceans. Building from decades of related research, new understandings of experimental cultures and natural biological systems are refining and redirecting our views. Additional opportunities for fingerprinting ancient microbial activities and their consequences lie with studies measuring all four sulfur isotopes $\left({ }^{32} \mathrm{~S},{ }^{33} \mathrm{~S},{ }^{34} \mathrm{~S},{ }^{36} \mathrm{~S}\right)$. 


\section{Anaerobic Oxidation of Methane (AOM): A Case Study of Coupled Microbial Cycling}

The potential for fundamental links between the microbial carbon and sulfur cycles in marine environments is illustrated by AOM: anaerobic oxidation of methane. First suggested based on geochemical profiles in marine sediments, the process of AOM remained elusive for years because no microorganism capable of mediating this reaction could be isolated. Eventually consortia of methane-oxidizing archaea and sulfate-reducing bacteria were found that mediate this reaction through nutritional interdependence (syntrophy: e.g. Boetius et al. 2000). Importantly, the consumption by AOM of sub-seafloor methane can limit methane release to the water column (and atmosphere), and it is therefore a critical process regulating global climate. However, much is still unknown about AOM, including the metabolic intermediates exchanged by the two partners, as well as the actual reactions performed by each (Milucka et al. 2012).

How methane is and was cycled on Earth carries tremendous implications for our understanding of past and present climate. Considering that the Precambrian-aged sun was only 70 to $90 \%$ as bright as it is today, methane and its photochemical products are invoked in most atmospheric models as key greenhouse modulators of early habitability. Studies in the lab and modern oceans, however, reveal that methane availability through time should tie very strongly to the availability of sulfate in the oceans, which in turn mirrors levels of biospheric $\mathrm{O}_{2}$.

For example, oxygen is a driver of sulfide weathering on the continents and thus sulfate delivery to the oceans. At the same time, the prevailing redox state of the oceans and, specifically, the loss of sulfate through pyrite burial is the dominant sulfate removal term. (Pyrite burial begins with MSR under anaerobic conditions and is generally less favored in high $\mathrm{O}_{2}$ oceans.) Higher levels of sulfate in the oceans mean more associated microbial sulfate reduction and, thus, less availability of labile organic phases to support methanogenic microorganisms (organic matter is oxidized as sulfate is reduced). More sulfate also means more methane loss via AOM. Once again, we see the intimate cause-and-effect relationship between microbial ecology and environmental change on the largest scale.

\section{Nitrogen Cycling}

Nitrogen is another vital ingredient for life. Nitrogen cycling is tightly linked with that of carbon and is controlled by biological transformations involving redox reactions. Two key biological innovations in the nitrogen cycle were the evolution of $\mathrm{N}_{2}$ fixation, which is the primary source of "fixed" nitrogen to the biosphere, and the proliferation of the aerobic nitrogen cycle. $\mathrm{N}_{2}$ fixation is the biological conversion of atmospheric $\mathrm{N}_{2}$ to bioavailable 
reduced nitrogen (ammonium, $\mathrm{NH}_{4}^{+}$) and is accomplished by specialized prokaryotes utilizing the nitrogenase metallo-enzyme complex, which contains iron and molybdenum in its most efficient form. Once fixed, ammonium is either rapidly recycled in the water column or is oxidized to nitrite $\left(\mathrm{NO}_{2}{ }^{-}\right)$and nitrate $\left(\mathrm{NO}_{3}^{-}\right)$, providing an additional nutrient source for primary producers. Further cycling returns nitrogen back to the atmosphere via a variety of processes, including denitrification (reduction of $\mathrm{NO}_{3}^{-}$) and anammox (anaerobic ammonium oxidation with $\mathrm{NO}_{2}^{-}$) (FIG. 3). These pathways of nitrogen "loss" have heterogeneous spatial and temporal distributions in the modern oceans-distributions we are only beginning to understand.

Like sulfur and carbon, evidence for the evolution of nitrogen cycling is based on its isotopic composition of ancient sediments $\left(\delta^{15} \mathrm{~N}\right)$. Nitrogen transformations produce measureable changes in the $\delta^{15} \mathrm{~N}$ of the associated compounds, which are reflected in the $\delta^{15} \mathrm{~N}$ of primary producers that utilize them (FIG. 3). Sedimentary organic nitrogen (and, to a lesser extent, clay-sorbed $\mathrm{NH}_{4}{ }^{+}$,) can reliably record these $\delta^{15} \mathrm{~N}$ values with minimal alteration in lowmetamorphic-grade sedimentary rocks. The $\delta^{15} \mathrm{~N}$ record shows considerable variation over geologic time (FIG. 3) and has a number of distinct characteristics, including the regular occurrence of very negative $\delta^{15} \mathrm{~N}$ values in sediments deposited before $\sim 2.5 \mathrm{Ga}$ and a shift toward positive $\delta^{15} \mathrm{~N}$ values-similar to modern ones-in sediments younger than $\sim 2.0 \mathrm{Ga}$.

The very negative $\delta^{15} \mathrm{~N}$ values detected in Archean sediments are not found anywhere on Earth today and are thought to reflect an anaerobic nitrogen cycle dominated by $\mathrm{N}_{2}$ fixation and/or the uptake of a large pool of bioavailable ammonium in anoxic oceans. The evolutionary onset of biological $\mathrm{N}_{2}$ fixation is uncertain, but a rapidly expanding biosphere on the early Earth would have quickly outpaced the limited abiotic sources of fixed nitrogen; sedimentary $\delta^{15} \mathrm{~N}$ values from $>3 \mathrm{Ga}$ are consistent with $\mathrm{N}_{2}$ fixation as the primary source of nitrogen to the biosphere (Stüeken et al. 2015). Highly ${ }^{15} \mathrm{~N}$-depleted biomass has been experimentally linked to ammonium uptake at high $\mathrm{NH}_{4}{ }^{+}$concentrations (Hoch et al. 1992) and to $\mathrm{N}_{2}$ fixation in a diverse group of photoautotrophs and chemoautotrophs, life forms that could have been important contributors to marine organic matter in anoxic, iron-rich oceans (Zerkle et al. 2008; Zhang et al. 2013). However, there are still significant gaps in our calibration of these fractionations.

An observed increase in $\delta^{15} \mathrm{~N}$ values between $\sim 2.5$ and 2.0 Ga coincides roughly with the GOE and is generally interpreted to reflect the transition to a modern-type aerobic nitrogen cycle dominated by nitrate-dependent processes of nitrogen loss (which return ${ }^{15} \mathrm{~N}$-depleted biomass to the atmosphere, leaving the marine nitrate pool relatively enriched). Positive $\delta^{15} \mathrm{~N}$ in the modern oceans requires a significant pool of nitrate in order for these 
fractionations to be expressed. Therefore, the timing of this shift at $\sim 2.5$ Ga presumably represents a tipping point in the balance of nitrate to ammonium rather than a specific evolutionary event. Small increases in $\delta^{15} \mathrm{~N}$ values in shales older than $\sim 2.5$ Ga may reflect a temporary onset of aerobic nitrogen cycling during transient oxygenation.

Further complicating this evolutionary history are recent indications of anaerobic pathways for ammonium oxidation in marine sediments using Fe(III) or Mn(IV) oxides instead of $\mathrm{O}_{2}$. The importance of these pathways and their associated $\delta^{15} \mathrm{~N}$ fractionations are unconstrained even in modern environments but presumably could have been widespread on an anoxic early Earth. Anaerobic nitrification can negate the need for molecular $\mathrm{O}_{2}$ to produce nitrate/nitrite, allowing for the existence of fixed-nitrogen-loss pathways even earlier in Earth's history. Having said that, the current understanding is that appreciable formation of manganese oxide requires $\mathrm{O}_{2}$ (Crowe et al. 2013).

Enhanced nitrate availability could have accelerated the marine nitrogen cycle by several orders of magnitude, further driving carbon fixation and oxygen production. However, the subsequent proliferation of denitrification and other nitrate-dependent pathways would have increased the loss of nitrogen from the marine environment. The critical consequence may have been a hindering of primary production through nutrient limitation if $\mathrm{N}_{2}$ fixation could not keep up, possibly due to a scarcity of trace metals or other micro-nutrients (discussed below). Determining the relative timing of these events in Earth history is, thus, crucial to understanding the feedbacks between the global cycling of nutrients during the progressive oxygenation of Earth's surface. With each step forward, new debates and opportunities emerge. Not surprisingly, interest in the early nitrogen cycle is at an all-time high.

\section{Changing Metal Inventories}

Shifts in metal availability with evolving ocean redox could have significantly affected early life. These metals are involved in enzymes that mediate nearly all of the biochemical processes described above. The role of trace metals in the nitrogen cycle, for example, has received considerable attention primarily because the metal cofactors of the primary nitrogenase enzyme (molybdenum and iron) and the denitrification pathway (iron and copper) are removed from solution in sulfide-rich environments (Anbar and Knoll 2002), a condition that expanded during the middle part of Earth history. This relationship spawned the controversial idea (discussed below) that alternative forms of the nitrogenase enzyme, which utilize either vanadium-iron ( $V n f$ ) genes or those requiring iron alone (Anf), could have been more important in Earth's early oceans (or even as a precursor to the primary Nif 
gene), following an evolutionary sequence that responded to bioessential trace metal availability, particularly the abundance of iron that is hypothesized to have been dominant in the oceans of the Archean.

Iron and zinc are almost universally required for life, due to their respective use in electron transfer and DNA synthesis. In our well-oxygenated modern world, iron limits the productivity of algae and bacteria in large portions of the oceans. Other metals have more specialized uses in biology, confined to key metabolic reactions that drive the biogeochemical cycling of major elements in the Earth system. For example, nickel and copper are important in the production and consumption of methane, respectively, and temporal variations in the bioavailability of these metals could have had significant consequences for atmospheric chemistry and global climate on the early Earth (e.g. Konhauser et al. 2009).

It is possible that nickel was more abundant in the pre-GOE early oceans because of its richness in early ultramafic (komatiitic) volcanism. With time (via a cooling Earth interior and a concomitant diminishing of ultramafic volcanism at Earth's surface), less nickel in weathering rocks might have meant less nickel available for methanogenesis (Konhauser et al. 2009). Consequently, less methane, which is a greenhouse gas and an important $\mathrm{O}_{2}$ sink, could have triggered (or at least contributed to) the rise in atmospheric $\mathrm{O}_{2}$ at the GOE and sent the Earth into a deep (snowball) freeze. Other researchers have argued the oppositethat the rise in $\mathrm{O}_{2}$ at the GOE came first, triggering the loss of methane and the associated climatic response.

Previous estimates for metal supplies in the early oceans have been mostly theoretical and based on thermodynamic predictions tied to oversimplified views of the varying redox state of the early oceans-specifically, a progression from almost exclusively anoxic/iron-rich (ferruginous) to anoxic/sulfidic (euxinic) to oxic waters. Now, we have a more textured view in time and space of that redox landscape (as reviewed in Lyons et al. 2014) thanks in part to more continuous data sets for a broader array of constituents, including trace metals. Moreover, experimental and numerical techniques are readily available to convert the geochemical data sets into more direct (quantitative, in the ideal) estimates of metal concentrations in ancient seawater via the analysis of diverse sample types (e.g. Scott et al. 2008; Konhauser et al. 2009). The new estimates point to possible metal limitations in the early oceans, as might be the case for molybdenum (Reinhard et al. 2013).

The relationship between molybdenum and nitrogen cycling gives us a perfect example by which to discuss the coevolution of microbial life and the environment, wherein biotic 
divergence is both driven by and a driver of first-order environmental change. The initial rise of oxygenic photosynthesis and associated $\mathrm{O}_{2}$ accumulation in the atmosphere gives us a good example of such a relationship -in this case a positive feedback. A more oxidizing atmosphere would have stimulated oxidative continental weathering, which in turn would have delivered bioessential molybdenum to the oceans-thus favoring $\mathrm{N}_{2}$ fixation, enhancing photosynthetic productivity in the oceans and potentially generating greater $\mathrm{O}_{2}$ release to the biosphere.

During the mid-Proterozoic, however, low oxygen conditions in the oceans could have favored the loss of biologically accessible fixed nitrogen via the processes described above. At the same time, molybdenum (an essential ingredient in nitrogenase for additional $\mathrm{N}_{2}$ fixation) would have been stripped from the water column by sulfide during widespread euxinia (Reinhard et al. 2013). The paucity of bioavailable nitrogen might then have stifled primary production, resulting in reduced burial of organic matter and associated release of $\mathrm{O}_{2}$ to the oceans and atmosphere. The net result would have been the environmental, geochemical, and biotic stasis famously assumed for the "boring" billion years of the midProterozoic.

\section{PHYLOGENOMIC ADVANCES}

Additional perspectives on ancient microbes lie at the intersection between genomics and evolution. Continuing with the nitrogen theme as an example, the evolution of $\mathrm{N}_{2}$ fixation can be investigated via the genes for nitrogenase and the associated biosynthetic pathways in extant organisms. Phylogenetic reconstructions of associated genes support the early emergence of the nitrogenase enzyme in an anoxic environment, possibly in a methanogen (Boyd and Peters 2013). The nitrogenase enzyme is irreversibly destroyed by $\mathrm{O}_{2}$. These observations suggest that primary molybdenum-bearing nitrogenase likely preceded alternative forms. This inference is based on several lines of evidence, including that alternative nitrogenase enzymes only occur in a small number of organisms and always secondarily to the primary iron-molybdenum version. Furthermore, gene clusters encoding for $V n f$ and $A n f$ are missing important structural genes, which implies a dependence on Nifbased machinery, and there are phylogenetic reconstructions consistently indicating that $\mathrm{Nif}$ evolved before the alternative enzymes (Boyd and Peters 2013).

Although it is a valid hypothesis that alternative nitrogenases contributed to $\mathrm{N}_{2}$ fixation in early anoxic environments, an early dominance of $\mathrm{Nif}$ is also supported by new $\delta^{15} \mathrm{~N}$ records from the early Archean (Stüeken et al. 2015). What this means for the nitrogen cycle on the early Earth is that molybdenum-based $\mathrm{N}_{2}$ fixation evolved and locally supported high levels 
of productivity in oceans that might have been generally molybdenum-poor. Recent related efforts have sought to tie phylogenomic datasets to independent geochemical estimates of microbial innovation (such as the earliest bacterial production of $\mathrm{O}_{2}$ ), associated environmental shifts (marine redox), and inferred trace metal availability (Dupont et al. 2010).

\section{ORGANIC BIOMARKERS}

Analysis of organic compounds from the Archean and the Paleoproterozoic can be hindered by the high degrees of alteration (notably, high burial temperatures) that those samples have experienced. Nevertheless, organic approaches are both valid and important when we reconstruct early microbial ecosystems, even in very old rocks. For example, the wide range of Archean organic carbon isotope signatures, particularly the abundance of highly negative values (characteristic of ${ }^{13} \mathrm{C}$-depleted methane), are unusual relative to younger rocks and possibly reflect a robust record of pervasive methane cycling. The subsequent increase in organic-C isotope values in late Archean kerogen might reflect the increasing role of aerobic respiration $\left(\mathrm{O}_{2}\right.$-dependent microbial degradation of organic matter; Eigenbrode and Freeman 2006) - a hypothesis consistent with the temporal proximity of the GOE.

Biomarkers emerge more clearly as tracers of microbial ecology during the mid-Proterozoic, including suggestions of anoxygenic photosynthesis via sulfide-oxidizing green and purple sulfur bacteria within shallow euxinic waters (Brocks et al. 2005). This microbial activity may have been an important pathway of primary production of biomass that helped sustain deep-water anoxia (Johnston et al. 2009). The data of Brocks et al. (2005) also suggest high levels of methane cycling, as might be expected under the low sulfate conditions generally assumed for mid-Proterozoic seawater. These settings, in general, were dominated by bacterial primary productivity, in the absence of any convincing biomarker data for eukaryotes. By the late Proterozoic, however, organic molecular records offer windows through which we see increasing biotic complexity-as is also observed in the fossil records - that reflects larger and more diverse eukaryote populations. The late Proterozoic molecular records include steranes derived from the breakdown of eukaryotic sterols within diversifying and growing algal populations and the earliest animals (Love et al. 2009).

\section{FUTURE DIRECTIONS}

The recent advances in microbial biogeochemistry have not only been revelatory but have also pointed to inevitable gaps in our knowledge. But these gaps are an inspiration, driving the scientific community to revisit long-held assumptions with eight new research goals, among many others: 
- Construct chemical/biological connections between the nitrogen cycle and other biogeochemical cycles-such as autotrophic denitrification with sulfide, anammox coupled to anaerobic oxidation of methane, and the cryptic sulfur cycle-with more and better experiments and analysis of an expanded array of modern oxygendeficient settings.

- Constrain the evolution of nitrogen metabolisms by additional phylogenetics and/or molecular clocks. One goal is to better understand the presence versus predominance among the possible pathways of $\mathrm{N}_{2}$ fixation.

- Refine the constraints on biological fractionation of stable isotopes (especially for $\delta^{15} \mathrm{~N}$ ) across a greater variety of organisms and across a range of environmental conditions, thereby increasing the utility of isotopic tools.

- Advance frontiers in sulfur geochemistry by using tools that resolve microscale isotopic variability under natural and controlled experimental conditions and by finding the linkages between micro- and bulk-sample measurements that can guide our modeling of biospheric evolution at the largest spatial and temporal scales.

- Integrate multiple microbial isotopic biosignatures and evaluate them within a robust context of other complementary proxies. This integrated context should include sophisticated petrographic, paleontological, sedimentological, elemental/organic geochemical, and diagenetic approaches, all of which should reveal local versus global controls, high-resolution temporal patterns, and the potential effects of signal resetting during long-term burial.

- Establish quantitative and process-based constraints on trace metal, phosphorus, and macronutrient concentrations in the early oceans. With increasingly sophisticated experiments using microorganisms, there is the possibility of better defining the micro- and macronutrient limitations in the past.

- Bridge a new generation of "omic" data with greater frequency and rigor with independent constraints on evolving background environments and geochemical fingerprints of microbial activity. The highest hope is for full reconciliation among phylogenetic predictions for the timing and sequence of microbial innovation, environmental factors, and historical records of microbial evolution and proliferation that has been captured in the fossil and geochemical data. 
- Determine microbial oxidation pathways under anaerobic conditions to construct a fundamentally new understanding of the biogeochemical cycles for a diverse range of elements. These pathways, and their geochemical expressions, will continue to change our understanding of ancient ecologies.

Never before have uniformitarian efforts been stronger, nor have the future opportunities been clearer. Our understanding of the intersection between microbes and the environment is advancing at an unprecedented rate. New analytical techniques calibrated in the lab and modern aquatic environments and grounded in an increasingly sophisticated and integrated view of microbial metabolisms are showing us the way. Indeed, the interfaces among environmental microbiologists, experimentalists, geologists, and biogeochemists are the keys to a better understanding of our prokaryotic past.

What is more, the many different microbe-dominated habitable states in Earth's past are guiding our exploration for life elsewhere within our Solar System and beyond. This marriage across diverse timescales and regions of interest, incorporating the diversities of organic and inorganic Earth materials involved and with implications that reach from atomic to global, is the very definition not only of geomicrobiology but also of astrobiology. When we ultimately find a biosignature for life beyond our planet, it is almost certainly going to be microbial. And perhaps it will be very much like those described from the early Earth-our versatile test bed in one of science's greatest explorations.

Acknowledgments: This work was supported by the NASA Astrobiology Institute under Cooperative Agreement No. NNA15BB03A issued through the Science Mission Directorate (TWL), a Natural Environment Research Council Fellowship (NE/H016805) (AZ), and National Science Foundation grants (EAR-0951509, OCE-1061476, EAR-1124389, and OCE1155346) and a Packard Fellowship (DAF). The authors are grateful to co-editors Greg Dick and Greg Druschel for their many efforts in preparing this issue and to Trish Dove for excellent editorial suggestions.

\section{REFERENCES}

Anbar AD, Knoll AH (2002) Proterozoic ocean chemistry and evolution: A bioinorganic bridge? Science 297: 1137-1142

Boetius A, and 9 coauthors (2000) A marine microbial consortium apparently mediating anaerobic oxidation of methane. Nature 407: 623-626 
Boyd ES, Peters JW (2013) New insights into the evolutionary history of biological nitrogen fixation. Frontiers in Microbiology 4: 1-12

Brocks, JJ and 5 coauthors (2005) Biomarker evidence for green and purple sulphur bacteria in a stratified Palaeoproterozoic sea. Nature 437: 866-870

Canfield DE, Farquhar J, Zerkle AL (2010) High isotope fractionations during sulfate reduction in a low-sulfate euxinic ocean analog. Geology 38: 415-418

Canfield DE, Teske A (1996) Late Proterozoic rise in atmospheric oxygen concentration inferred from phylogenetic and sulphur-isotope studies. Nature 382: 127-132

Crowe $S$ and 6 coauthors(2013) Atmospheric oxygenation three billion years ago. Nature 501: 535-538

Crowe SA and 11 coauthors (2014) Sulfate was a trace constituent of Archean seawater. Science 346: 735-739

Dupont CL, Butcher A, Valas RE, Bourne PE, Caetano-Anollés G (2010) History of biological metal utilization inferred through phylogenomic analysis of protein structures. Proceedings of the National Academy of Sciences of the United States of America 107: 10567-10572

Eigenbrode JL, Freeman KH (2006) Late Archean rise of aerobic microbial ecosystems. Proceedings of the National Academy of Sciences of the United States of America 103: 15759-15764

Fike DA and 5 coauthors (2009) The effect of sulfate concentration on (sub)millimeterscale sulfide $\delta^{34} S$ in hypersaline cyanobacterial mats over the diurnal cycle. Geochimica et Cosmochimica Acta 73: 6187-6204

Godfrey LV, Falkowski PG (2009) The cycling and redox state of nitrogen in the Archaean ocean. Nature Geoscience 2: 725-729

Heimann A and 6 coauthors (2010) Fe, C, and O isotope compositions of banded iron formation carbonates demonstrate a major role for dissimilatory iron reduction in $\sim 2.5$ Ga marine environments. Earth and Planetary Science Letters 294: 8-18

Hoch MP, Fogel ML, Kirchman DL (1992) Isotope fractionation associated with ammonium uptake by a marine bacterium. Limnology and Oceanography 37: 1447-1459

Johnston DT, Wolfe-Simon F, Pearson A, Knoll AH (2009) Anoxygenic photosynthesis modulated Proterozoic oxygen and sustained Earth's middle age. Proceedings of the National Academy of Sciences of the United States of America 106: 16925-16929

Kappler A, Pasquero C, Konhauser KO, Newman DK (2005) Deposition of banded iron formations by anoxygenic phototrophic Fe(II)-oxidizing bacteria. Geology 33: 865868

Konhauser KO and 8 coauthors (2009) Oceanic nickel depletion and a methanogen famine before the Great Oxidation Event. Nature 458: 750-753 
Krissansen-Totton J, Buick R, Catling DC (2015) A statistical analysis of the carbon isotope record from the Archean to Phanerozoic and implications for the rise of oxygen. American Journal of Science 315: 275-316

Love GD and 12 coauthors (2009) Fossil steroids record the appearance of Demospongiae during the Cryogenian period. Nature 457: 718-721

Lyons TW, Reinhard CT, Planavsky NJ (2014) The rise of oxygen in Earth's early ocean and atmosphere. Nature 506: 307-315

Milucka J and 9 coauthors (2012) Zero-valent sulphur is a key intermediate in marine methane oxidation. Nature 491: 541-546

Planavsky NJ and 15 coauthors (2014a) Evidence for oxygenic photosynthesis half a billion years before the Great Oxidation Event. Nature Geoscience 7: 283-286

Planavsky NJ and 8 coauthors (2014b) Low mid-Proterozoic atmospheric oxygen levels and the delayed rise of animals. Science 346: 635-638

Reinhard CT and 8 coauthors (2013) Proterozoic ocean redox and evolutionary stasis. Proceedings of the National Academy of Sciences of the United States of America 110: 5357-5362.

Scott C and 6 coauthors (2008) Tracing the stepwise oxygenation of the Proterozoic ocean. Nature 452: 456-459

Shen Y, Buick R, Canfield DE (2001) Isotopic evidence for microbial sulphate reduction in the early Archaean era. Nature 410: 77-81

Sim MS, Ono S, Donovan K, Templer SP, Bosak T (2011) Effect of electron donors on the fractionation of sulfur isotopes by a marine Desulfovibrio sp. Geochimica et Cosmochimica Acta 75: 4244-4259

Stüeken EE, Buick R, Guy BM, Koehler MC (2015) Isotopic evidence for biological nitrogen fixation by molybdenum-nitrogenase from 3.2 Gyr. Nature 520: 666-669

Zerkle AL, Junium CK, Canfield DE, House CH (2008) Production of ${ }^{15} \mathrm{~N}$-depleted biomass during cyanobacterial $\mathrm{N}_{2}$-fixation at high Fe concentrations. Journal of Geophysical Research 113: G03014, doi: 10.1029/2007JG000651

Zhang X, Sigman DM, Morel FMM, Kraepiel AML (2014) Nitrogen isotope fractionation by alternative nitrogenases and past ocean anoxia. Proceedings of the National Academy of Science of the United States of America 111: 4782-4787 


\section{FIGURE CAPTIONS}

FIGURE 1 A fossil-based and isotopic, elemental, and organic geochemical perspective on the distributions of microbial metabolisms and other (environmental) milestones over Earth's history. The observed timing relationships and signal strengths among the records, including any offsets with phylogenetic predictions, may reflect varying population size and diversity that is biased by prevalence and persistence of favorable environments against a backdrop of incomplete sampling and preservational artifacts. The small tick marks on the timescale define 500-million-year increments moving backward in time (from right to left) from the present day. The thick pink vertical lines delineate the Great Oxidation Event and the Neoproterozoic Oxidation Event. Phan. $=$ Phanerozoic.

FIGURE 2 Major microbial sulfur cycling metabolisms and associated redox transformations: first, sulfate reduction (blue) transforms sulfate to hydrogen sulfide; second, sulfide oxidation (green) transforms sulfide to a more oxidized state between elemental sulfur ( $\mathrm{S}^{0}$ ) and sulfate; and third, disproportionation transforms (red) of elemental sulfur, or another intermediate-valence sulfur species, to $\mathrm{H}_{2} \mathrm{~S}$ and $\mathrm{SO}_{4}{ }^{2-}$. Representative isotopic fractionations (expressed as $\varepsilon$, measured in permil) associated with these transformations are shown.

FIGURE 3 Temporal trends for nitrogen isotope data over geologic time for organic (kerogen), mineral (clay-bound $\mathrm{NH}_{4}^{+}$), and bulk-rock nitrogen. Insert shows associated nitrogen cycling processes and $\delta^{15} \mathrm{~N}$ effects. During the Archean, the nitrogen cycle was likely dominated by $\mathrm{N}_{2}$ fixation and ammonium cycling in an anaerobic biosphere, producing highly ${ }^{15} \mathrm{~N}$-depleted sedimentary $\delta^{15} \mathrm{~N}$ values that disappear completely from the subsequent rock record except during periods of expanded oceanic anoxia in the Phanerozoic (Phan.) (red data and pathways). The modern-type nitrogen cycle, dominated by nitrate-dependent nitrogen loss processes, proliferated after the Great Oxidation Event ( $\sim 2.3$ to $2.4 \mathrm{Ga}$; blue data and pathways). Green pathways highlight the occurrence of new or under-studied nitrogen metabolisms for which we have little or no current understanding, such as anaerobic nitrification and chemotrophic denitrification pathways. Data compiled from references in Stüeken et al. (2015). 